\title{
MATHEMATICAL MODELS IN ECONOMICS
}

\section{Wei-Bin Zhang}

Ritsumeikan Asia Pacific University, Oita-ken 874-8577, Japan

Keywords: chaos, core trade theorems, creative destruction, business cycle, education, factor price equalization theorem, Heckscher-Ohlin theorem, general equilibrium, Keynesian economics, learning by doing, Malthus' population theory, monetary economic growth, multi-sector growth model, neoclassical growth theory, OLG model, preference change, Ramsey growth model, Ricardo's economic theory, Schumpeterian growth, Solow growth model, Tobin's model, trade theory, von Thünen's spatial economics.

\section{Contents}

1. Introduction

2. A Modern Treatment of Walras' General Equilibrium Theory

3. A Generalization of Ricardo’s Economic Theory

4. A Generalization of Malthus' Population Dynamics with Chaos

5. Von Thünen's Spatial Economics and a Short-Run Dynamics of Land Prices

6. The Ramsey Growth Model and Neoclassical Growth Theory

7. Monetary Economic Growth and Business Cycles

8. A Growth Model with Solow's and Schumpeter's Growth Mechanism

9. Growth with Arrow's Learning by Doing and Uzawa's Education

10. A Nonlinear Keynesian Economic Dynamics and Chaos

11. Traditional Trade Theories and the Core Trade Theorems

12. On Gneralization of Economic Theories

Acknowledgements

Glossary

Bibliography

Biographical Sketch

\section{Summary}

The purpose of this chapter is to introduce the theme, Mathematical Models in Economics and explain the arrangement of the topic chapters of the theme. The topic chapters are classified according to economic issues. Since the literature on the theme is vast, this chapter is concentrated on modern versions of some classical economic theories, taking account of balancing between significance of economic issues and mathematical techniques.

\section{Introduction}

"... the sciences are like a beautiful river, of which the course is easy to follow, when it has acquired a certain regularity; but if one wants to go back to the source, one will find it nowhere, because it is everywhere; ... it is the same if one wants to go back to the origin of the sciences, one will find only obscurity, vague ideas, vicious circles; and one loses oneself in the primitive ideas." 
The purpose of this chapter is to provide an introduction to applications of mathematics to economics. After World War II, mathematical economics has experienced rapid growth, generating many new academic fields associated with the development of mathematical theory and computer. Mathematics is the backbone of modern economics. It plays a basic role in creating ideas, constructing new theories, and empirically testing ideas and theories. Mathematics is now an integral part of economics. The main advances in modern economics are characterized by applying mathematics to various economic problems. Many of today's profound insights into economic problems could hardly be obtained without the help of mathematics. The concepts of equilibrium versus non-equilibrium, stability versus instability, and steady states versus chaos in the contemporary literature are difficult to explain without mathematics.

The purpose of this chapter is to introduce Theme, Mathematical Models in Economics. We arrange the topic chapters of the theme according to questions of economic problems. The chapters of the Theme consists of the following subject articles: Introduction to Mathematical Economics (Tönu Puu), Mathematical Models in InputOutput Economics (Faye Duchin and Albert Steenge), Economic Dynamics (Wei-Bin Zhang), Econometric Methods (Roselyne Joyeux and George Milunovich), General Equilibrium (Monique Florenzano), Labour Market Analysis: Issues and Facts (Arup Mitra), Household Behavior and Family Economics (Olivier Donni), Welfare Theory: History and Modern Results (Thomas Aronsson and Karl-Gustaf Lofgren), Social Choice (Norman Schofield), Mathematical Modelling in Agricultural Economics (Richard E. Just), Models of Economic Growth (Alfred Greiner), Mathematical Models of Environmental Economics Modelling in Agricultural Economics (Franz Wirl), Money in Economic Analysis (Toichiro Asada), Models of International Economics (Giancarlo Gandolfo), Growth, Development, and Technological Change (Volker Grossmann and Thomas M. Steger), Innovation and Economic Dynamics (Walter G. Park), Growth and Development with Income and Wealth Distribution (Dipankar Dasgupta), Mathematical Models of Transportation and Networks (Anna Nagurney), Mathematical Models in Regional Economics (Peter Nijkamp and Jacques Poot), Mathematical Models of Resource and Energy Economics (Ngo Van Long), and Mathematical Models in Spatial Economics (Åke E Andersson and Borje Johansson).

Tönu Puu (see Introduction to Mathematical Economics) introduces the field with a broad vision. Accordint to Puu, although the contemporary mathematical economics cannot be summarized due to its great variety, mathematical economics is the application of mathematical methods in economic theory. In fact, Puu emphasizes Schumpeter's warning that economists working with mathematics as a tool cannot be defined as a school. The chapter describes the historical origins of the use of mathematical analysis in economics, dating from early 19th Century untill the present. In particular, Puu discusses the contents of the typical treatises (written untill the mid 20th Century), which reflect the totality of applications of mathematics to economics by the time when they were published.

The chapter of Faye Duchin and Albert Steenge (see Mathematical Models in InputOutput Economics) describes the mathematical basis for input-output economics, the 
major types of models, and the underlying economic theory. It emphasizes these features of the input-output models that make them especially well suited for understanding the connections between the economy and the environment. The most important approaches to analysis involve multipliers, decomposition, and scenario analysis. The pape also introduces some extensions of the basic model which accommodate the representation of pollutant emissions and policies for constraining them, dynamic models, and multi-regional models, the latter including a new version of a world model that solves for bilateral trade flows and region-specific prices based on comparative advantage with factor constraints.

The purpose of the chapter by Wei-Bin Zhang (see Economic Dynamics) provides a comprehensive introduction of applications of differential and difference equations to economics. It introduces basic concepts and analytical methods and provides applications of these methods to solve economic problems. The chapter provides not only a comprehensive introduction to applications of theory of linear (and linearized) equations to economic analysis, but also studies nonlinear dynamic systems, which have been widely applied to economic analysis only in recent years. It is arranged according to dimensions of the dynamic systems. First, the chapter deals with scalar differential and difference equations. Next, it studies planar differential equations. Then, it introduces higherdimensional equations. The chapter examines key concepts and main mathematical results related to linear (linearized) and nonlinear equations and their applications to economics.

Roselyne Joyeux and George Milunovich (see Econometric Methods) provide a survey of econometric methods. The chapter presents an overview of those econometric methods and models that are most useful to an applied economist. Further, the chapter distinguishes between econometric methods, which are statistical estimation techniques and econometric models to which estimation methods are applied.

The purpose of the chapter by Monique Florenzano (see General Equilibrium) is to introduce general equilibrium theory, which analyzes the simultaneous equilibrium in all markets of a competitive economy. The chapter defines a general equlibrium model, examines some of its basic results, and provides insights from the model. The important issues of uniqueness and local uniqueness of equilibrium are sketched. The main extensions of the general equilibrium model are also reviewed. Besides the natural extensions to infinitely many commodities and to a continuum of agents, some examples show how economic theory can accommodate the main ideas in order to study some contexts which were not thought of by the initial model.

Arup Mitra (see Labour Market Analysis: Issues and Facts) reviews issues, models and empirical findings relating to labor economics. First, some of the general research questions are taken up in the context of labor demand and supply, which is followed by detailed discussions on rural and urban labor markets. In the rural context the agriculture and the non-farm sectors are analyzed separately. Four important streams of arguments in the context of urban labor market, namely the agglomeration economies framework, limited-industry based urbanization thesis, contact based migration and labor market segmentation theory and finally, the political vote bank theory are discussed in detail. Debates and differences in findings are brought out at the appropriate places. 
Olivier Donni (see Household Behavior and Family Economics) presents the most important models of household behavior. The introduction gives an overall picture of the literature. The first part of the text is concerned with the behavior of single-person households. The classical models of goods demand and of labor supply as well as their extension to domestic production are discussed here. The second part considers the behavior of multi-person households. The traditional (also called unitary) approach in that case consists in ignoring the differences that may exist between single-person and multi-person households, and analyzing the behavior of the latter as if there were a wellbehaved utility function at the household level. The chapter also introduces other ways of modeling the behavior of multi-person households. The conclusion discusses heterodox approaches (issued from Marxism and feminism) to household behavior.

The purpose of the chapter by Thomas Aronsson and Karl-Gustaf Lofgren (see Welfare Theory: History and Modern Results) is to provide an overview of modern welfare theory. First, the chapter gives a historical perspective on the questions dealt with in a more formal way later on. Then, it deals with issues and tools that any user of modern welfare theory must be aware of, such as the First and Second Welfare Theorems, Arrow's Impossibility Theorem, and situations where the markets themselves do not give rise to an optimal resource allocation from society's point of view. The chapter also introduces social accounting and the associated problem of measuring welfare - a growing area of research in welfare economics - as well as introduced methods for cost benefit analysis in dynamic economies.

The purpose of the chapter by Norman Schofield (see Social Choice) is to introduce modern social choice theory. Arrows Impossibility implies that any social choice procedure that is rational and satisfies the Pareto condition will exhibit a dictator, an individual able to control social decisions. If instead all that we require is the procedure gives rise to an equilibrium, core outcome, then this can be guaranteed by requiring a collegium, a group of individuals who together exercise a veto. On the other hand, any voting rule without a collegium is classified by the Nakamura number. If the number of alternatives does not exceed the Nakamura number, then an equilibrium can always be guaranteed. In general, majority rule has Nakamura number of 3 , so an equilibrium can only be guaranteed in one dimension.

Richard E. Just (see Mathematical Modelling in Agricultural Economics) emphasizes that the discipline of agricultural economics has played a pioneering role in the application of mathematical models in economics. Mathematical programming techniques were developed to offer normative advice to farmers. Eventually, programming models were expanded to offer advice at regional and national levels on issues as diverse as commercial agricultural policy, environmental policy, water and soil conservation policy, and public investment in infrastructure such as waterway and irrigation development. Agriculture was a natural application of stochastic and dynamic programming. The chapter also demonstrates that agricultural economics played a key role in the development and application of econometrics for positive modeling purposes. With a wide variety of reasonably competitive product markets and abundant public data, agriculture presented a ready field of application for various statistical regression techniques as they were developed. In more recent times, as contracting has replaced open market transactions, agriculture has become a ready laboratory for application of 
game theory and the principal-agent models of mechanism design that now dominate microeconomic analysis.

The chapter by Alfred Greiner (see Models of Economic Growth) surveys models of economic growth starting with the Harrod-Domar growth model, which is based on Keynesian ideas of incomplete markets, and continues with the neoclassical model of exogenous growth. A shortcoming of this model is that, which is an empirically observed fact in market economies, but has to resort to exogenously given technical change. The reason for this problem lies in the fact that the production function is characterized by a declining marginal product of physical capital which reduces the incentive to invest as capital rises. As a consequence, the economy converges to a steady state in the long-run where investment is just sufficiently high to keep the percapita capital stock constant. The endogenous growth theory overcomes the shortcoming associated with the neoclassical model that it cannot endogenously explain sustained per-capita growth by postulating that there exist endogenous factors that have positive effects on the marginal product of capital. The chapter depicts fundamental endogenous growth models starting with the model where investment is associated with positive externalities on the macroeconomic level. The article also discusses the dynamic behavior of the models presented and points out empirical evidence for each class of models.

Franz Wirl (see Mathematical Models of Environmental Economics Modelling in Agricultural Economics) surveys mathematical models and methods applied in environmental economics organized along environmental problems externalities and instruments, resource extraction, renewable resource management, the tragedy of the commons in general and in particular in the context of global warming. To deal with these selected topics, the methods of static optimization, partial equilibrium analysis, optimal control, real option and mechanism design are introduced. A particular aspect of this survey is the consideration of thresholds across different methods. Thresholds are a way to formalize the criterion of sustainability, which gives an ecological touch to the analysis. In addition to these more elaborate expositions, further topics such as (computable) general equilibrium models, valuation of environmental goods, corporate social responsibility, and public choice are briefly addressed.

Toichiro Asada (see Money in Economic Analysis) surveys the fundamental topics of money in economic analysis, especially money in standard microeconomic and macroeconomic theories. First, the definition and the functions of money as well as an earlier quantitative theory on money are introduced. Then, the roles of money in the mainstream microeconomic analysis and the Walrasian general equilibrium theory are examined. Tirdly, the theoretical treatment of demand and supply of money in Keynesian macroeconomics is analyzed. Finally, some fundamental topics on monetary analysis in the Keynesian and classical traditions are addressed.

Giancarlo Gandolfo (see Models of International Economics) observes that the importance of international economics is increasing, owing to the increasing openness of the single national economic systems: on average, at the world level more than $28 \%$ of national income is spent on foreign commodities and services. A feature of current international exchanges with respect to those of the past is that exchanges of financial 
assets have been growing much more rapidly than exchanges of commodities. Moreover, these financial exchanges, once ancillary to commodity trade, have taken on an autonomous importance and are far greater than the value of exchanges of commodities. This situation is also reflected in the theoretical models, which -once mostly concerned with the theory of commercial flows- have had to cope with the theory of financial and macroeconomic flows in an open macroeconomy. This chapter deals with mathematical models of both the theory and policy of international trade and with international monetary economics.

The chapter by Volker Grossmann and Thomas M. Steger (see Growth, Development, and Technological Change) surveys important chapters in the theory of endogenous technical change by focusing on the basic structure of endogenous growth models with horizontal as well as vertical innovation and emphasizing important implications for growth policy. Issues such as the scale effect problem, directed technological change to understand the evolution of wage inequality, long-run divergence between the innovating North and the imitating South due to inappropriate technology in the South, the relationship between trade and growth, competition and R\&D, and the role of imperfect capital markets for R\&D-based growth are examined.

Walter G. Park (see Innovation and Economic Dynamics) surveys recent economics research on innovation and dynamic change. First, an overview of different models of innovation is provided. The focus here is on models of product innovation, rather than process innovation. The former kind accounts for the bulk of innovative activities. Two types of innovation are considered: horizontal (expansion in the variety of goods) and vertical (improvements in the quality of goods). Second, applications of the models are provided. The focus of the applications is on policy-oriented issues; for example, the relationship between market size and innovation, which has implications for policies on economic integration, and the role of subsidies to research and development. Another policy issue is patent protection versus open innovation in which researchers do not seek patent rights but instead freely share inventions and discoveries.

The chapter by Dipankar Dasgupta (see Growth and Development with Income and Wealth Distribution) introduces some of the major developments in growth economics with income and wealth distribution over the last twenty years or so. It attempts to concentrate on a few chapters and brings out their essence. The mathematics is developed in an intuitive manner. Only a minimal level of prior training in mathematical techniques is necessary to read the chapter.

The chapter by Anna Nagurney (see Mathematical Models of Transportation and Networks) provides the foundations of the rigorous formulation, analysis, and solution of transportation network problems. It discusses user-optimization, which corresponds to decentralized decision-making, and system-optimization, which corresponds to centralized decision-making where the central controller can route the traffic in an optimal manner. It also examines a spectrum of increasingly sophisticated models and relates transportation networks to other network application domains in which flows (and associated decision-making) are essential, such as the Internet, supply chains, electric power distribution and generation networks, as well as financial networks. Finally, it is demonstrated how the importance of transportation network components, 
that is, nodes and links can be identified (and ranked) through a recently proposed transportation network efficiency measure and accompanying component importance definition.

Peter Nijkamp and Jacques Poot (see Mathematical Models in Regional Economics) review the evolution of mathematical and statistical models that have been used for the development of theory and policy analysis in regional economics. The benefits of mathematical approaches are outlined. Theories and estimation techniques have developed in tandem with developments in the availability of geo-referenced data, new technologies and particularly computing power. Regional modeling was initially strongly influenced by macro-econometric and input-output models developed for national economies, but evolved into models that integrated these approaches into multiregional settings that are often of a highly nonlinear nature and explicitly account for various forms of spatial interaction. New theoretical developments such as the new economic geography and endogenous growth theory have had a major impact on recent modeling trends and on the increasing popularity of spatial econometrics.

The chapter by Ngo Van Long (see Mathematical Models of Resource and Energy Economics) reviews major economic models of natural resources and energy use. The center-piece of the theory of non-renewable resource, Hotelling's Rule, is explained and various versions of it are derived. Herfindahl's Rule on the order of exploitation of deposits is shown to have limitations. This is followed by an exposition of equilibrium concepts in dynamic games involving natural resources. The role of imperfect property rights in the inefficient exploitation of resources is highlighted, and supported by models that predict or explain the extinction of some renewable resources. Some models of investment in energy efficiency are also reviewed.

Åke E Andersson and Borje Johansson (see Mathematical Models in Spatial Economics) introduce most of the important mathematical models in spatial economics, where the geography is represented by one-dimensional as well as two-dimensional space. The review concentrates on model families. A first family of such models deals with the determination of market areas and competition between the few in onedimensional and two-dimensional space, where firms decide about price and location simultaneously. The second family contains equilibrium flow models in twodimensional space, which depict location and specialization phenomena, interregional trade and spatial price equilibrium. The third family contains urban land-use models, for which both classical and recent contributions frequently employ a one-dimensional representation of space. The fourth model class relates to the so-called new economic geography and contains examples where each region is modeled as a monocentric onedimensional space where the global geography consists of a discrete set of such regions.

Different from the chapters mentioned above, this chapter provides a general overview of mathematical approaches to economic problems. This chapter tries to illustrate mathematical models in economics from a broad perspective, examining how the main economic systems are described with different branches of mathematics. Since the literature on the theme is vast, this introduction provides only some applications of mathematics to economics, balancing the significance of economic issues and mathematical techniques. Rather than producing an endless litany of reviewing "A was 
the first", this chapter will be concentrated on a few main economic theories and see how various economic theories are constructed with different mathematical methods. The rest of the chapter is organized as follows. Section 2 makes a general introduction to modern treatment of Walras' general equilibrium theory. In Section 3 we studt a generalization of Ricardo's economic theory. In Section 4, we demonstrate chaos in a discrete nonlinear population growth. Section 5 presents a modern version of von Thünen's spatial ecnomics. In Section 6 we stdy the Ramsey growth theory and the Solow growth model. Section 7 deals with monetary economic growth models with busicess cycles. Section 8 presents a model, which can explain both the Solow's and Schumpeter's growth mechanisn. Section 9 introduces an economic growth model with Arrow's learning by doing and Uzawa's human capital accumulation with education. In Section 10, we present a nonlinear Keynesian economic model which exhbits chaotic behavior. Section 11 studies international trade theoris and the core trade theorems. Section 12 concludes the chapter with a discussion on producing a general economic theory. The bibliography at the end of the chapter provides the reader with guidelines for further investigations.

\section{TO ACCESS ALL THE 77 PAGES OF THIS CHAPTER,} Visit: http://www.eolss.net/Eolss-sampleAllChapter.aspx

\section{Bibliography}

Aghion, P. and Howitt, P. 1992. “A Model of Growth through Creative Destruction,” Econometrica, 60: 323351. [An innovative and mathematical presentation of Schumperter's ideas about creative destruction.]

Alonso, W. 1964. Location and Land Use. MA., Cambridge: Harvard University Press. [The book presents the core model in modern urban economics - Alonson residential model.]

Araujo, A. and Scheinkman, H.A. 1977. "Smoothness, Comparative Dynamics and Turnpike Property," Econometrica, 45: 601-20. [An important paper on examining properties of the Ramsey growth theory.]

Arrow, K.J. 1962. “The Economic Implications of Learning by Doing.” Review of Economic Studies, 29: 155-73. [The seminar paper in the literature about economic growth with learning by doing.]

Arrow, K.J. and F.H. Hahn. 1971. General Competitive Analysis. San Francisco: Holden-Day, Inc. [A classical book on modern theory of general competitition.]

Beckmann, M. and Puu, T. 1985. “Spatial Economics: Density, Potential, and Flow,” Amsterdam: NorthHolland. [A comprehensive and unique approach to spatial economics with partial differential equations.]

Benhabib, J. and Nishimura, K. 1979. "The Hopf Bifurcation and the Existence of Stability of Closed Orbits in Multisector Models of Optimal Economic Growth,” Journal of Economic Theory, 21: 421-44. [An paper paper on identifying economic cycles in the Ramsey multisector growth model.]

Ethier, W.J. 1974. "Some of the Theorems of International Trade with Many Goods and Factors,” Journal of International Economics, 4: 199-206. [A conprehensive treatment of the core theorems in classical international trade theory.]

Frederick, S., Loewenstein, G. and O’Donoghue, T. 2002. Time Discontinuing and Time Preference: A Critical Review. Journal of Economic Literature, 40: 351-401. [A comprehensive survey on the limitations 
of the concept of time preference in the Ramsey growth theory.]

Fujita, M. 1989. Urban Economic Theory - Land Use and City Size. Cambridge: Cambridge University Press. [A most popular graduate textbook on urban economics.]

Grandmont, J.M. 1985. “On Endogenous Competitive Business Cycles,” Econometrica, 53: 535-72[A seminar work on modelling endogenous buciness cycles in a monetary economy.]

Haavelmo, T. 1954. A Study in the Theory of Economic Evolution. North-Holland: Amsterdam. [The book deals with some important issues related to long-term economic development.]

Haken, H. 1983.: Advanced Synergetics - Instability Hierarchies of Self-Organizing Systems and Devices. Berlin: Springer. [A comprehensive and advanced introduction to sysnegetics.]

Heckscher, E. 1919. “The Effect of Foreign Trade on the Distribution of Income,” Ekonomisk Tidskrift, 497512. [The seminar work for one of the most important international trade models - Heckscher-Ohlin trade model - in international trade theory.]

Jehle, G.A. and Reny, P.J. 1998. Advanced Microeconomic Theory. New York: Addison-Wesley. [An wellconstructed textbook on microeconomics.]

Jullien, B. 1988. "Competitive Business Cycles in an Overlapping Generations Economy with Productive Investment. Journal of Economic Theory." 46: 45-65. [An early nonlinear business cycle model with capital and money examined by nonlinear dynamical theory.]

Kuhn, T.S. 1977. The Essential Tension. Chicago: University of Chicago Press. [A book should be read by anyone who is interested in conflicting tendencies of innovation and tradition in science and scientific training.]

Lerner, A.P. 1952. "Factor Prices and International Trade," Economica, 19: 1-15. [The seminar paper on factor-price equalization theorem - one of the core theories in international trade theory.]

Li, T.Y. and Y. Yorke. 1975. “Period Three Implies Chaos,” American Mathematical Monthly, 82: 98592. [The seminal work on the Li-Yorke theorem.]

Lorenz, H.W. 1993. Nonlinear Dynamical Economics and Chaotic Motion. Berlin: Springer-Verlag. [A comprehensive study of nonlinear economics.]

Mas-Colell, A. 1985. The Theory of General Economic Equilibrium: A Differentiable Approach. Cambridge: Cambridge University Press. [A general treatment of the Walrasian theory with modern mathematics.]

Matsuyama, K. 1999. “Growing Through Cycle,” Econometrica, 67: 335-47. [The model shows how the the economic growth mechanisms in the neoclassical growth theory and Schumpeter's innovation with destruction can be integrated into a single analytical framework.].

Neugart, M. 2004. "Complicated Dynamics in a Flow Model of the Labor Market," Journal of Economic Behavior \& Organization, 53: 193-213. [The model identifies chaos in a modern version of the Keynesian theory.]

Nicola, P.C. 2000. Mainsteam Mathematical Economics in the 20th Century. Heidelberg: Springer-Verlag. [The book presents some of important contributions of the 20th century to economic theory in historical sequence, focusing on general equilibrium and macroeconomic dynamic models.]

Ohlin, B. 1933. Interregional and International Trade. Cambridge: Harvard University Press. [The seminar and comprehensive work for one of the most important international trade models - Heckscher-Ohlin trade model - in international trade theory.]

Ramsey, F. 1928. “A Mathematical Theory of Saving,” Economic Journal 38, 543-59. [The seminar paper for the Ramsey growth model.].

Rybczynski, T.M. 1955. "Factor Endowments and Relative Commodity Prices," Economica, 22: 336-41. [The seminar paper on Rybczynski theorem - one of the core theories in international trade theory.]

Samuelson, P.A. 1937. “A Note on Measurement of Utility,” Review of Economic Studies, 4: 155-61. [After the publication of the paper, the Ramsey utility has become the main tool in economic dynamic analysis .]

Samuelson, P.A. 1948. “International Trade and Equalisation of Factor Prices,” Economic Journal, 58: 163-84. 
[An important contribution to factor-price equalization theorem - one of the core theories in international trade theory.]

Samuelson, P.A. 1949. “International Factor-Price Equalisation Once Again,” Economic Journal, 59: 181-97. [An important contribution to factor-price equalization theorem - one of the core theories in international trade theory.]

Sidrauski, M 1967. "Rational Choice and Patterns of Growth in a Monetary Economy,” American Economic Review, 57: 534-44. [The first mathematical model of monetary economic growth with .rational behavioral foundation]

Solow, R. 1956. “A Contribution to the Theory of Economic Growth,” Quarterly Journal of Economics, 70: 65-94. [This is the seminal work for the Solow-Swan model. The model has been used as the core model of neoclassical growth theory.]

Solow, R. 2000. Growth Theory - An Exposition. New York: Oxford University Press. [The book reflects on the development of the neoclassical growth theory.]

Stolper, W. and Samuelson, P.A. 1941. "Protection and Real Wages,” Review of Economic Studies, 9: 58-73. [The seminar work the Stolper-Samuelson theorem - one of the core theories in international trade theory.]

Swan, T.W. 1956. "Economic Growth and Capital Accumulation,” Economic Record, 32: 334-61. [This is the seminal work for the Solow-Swan model. The model has been used as the core model of neoclassical growth theory.]

Stutzer, M. 1980. "Chaotic Dynamics and Bifurcation in a Macro Economics," Journal of Economic Dynamics and Control, 2: 253-73. [An early application of the logistical map to economic theory for identifying chaotic behavior.]

Takayama, A. 1985. Mathematical Economics. Cambridge: Cambridge University Press. [A well-known textbook on mathematical economics. It covers many topics of modern mathematical economics.]

Tobin, J. 1965. "Money and Economic Growth,” Econometrica, 33: 671-84. [The seminar work on modern monetary economic growth theory.]

Uzawa, H. 1965. "Optimal Technical Change in an Aggregative Model of Economic Growth,” International Economic Review, 6: 18-31. [The seminar work on introducing human capital accumulation by education to the Ramsey growth theory.]

Vinod, H.D. 1979. "Theory of the Diffusion of Price Inflation in Imperfect Market Similar to Housing, Having Delayed Arbitrage,” Environment and Planning A, 6: 369-409. [An original application of partial differential equations to housing market.]

Zhang, W.B. 1988a. "Urbanizing Processes With Moving Boundaries,” Geographical Analysis, 20: 32839. [An original application of partial differential equations to urban evolution with endogenous boundary.]

Zhang, W.B. 1988b. "Hopf Bifurcations in Multisector Models of Optimal Economic Growth," Economics Letters, 26: 329-34. [The paper identifies Hopf bifurcations in the Ramsey multisector growth models.]

Zhang, W.B. 1989. "Existence of Aperiodic Time-Dependent Solutions in Optimal Growth Economy With Three Sectors," International Journal of Systems Science. 20: 1943-53. [The paper identifies aperiodic time-dependent oscillations in the Ramsey three-sector growth models.]

Zhang, W.B. 1991. Synergetic Economics. Heidelberg: Springer-Verlag. [A systematical application of nonlinear theory to economics.]

Zhang, W.B. 1999. Capital and Knowledge - Dynamics of Economic Structures with Non-constant Returns: Springer-Verlag, Heidelberg. [The book proposes a new economic growth theory based on an alternative utility function proposed by Zhang.]

Zhang, W.B. 2005. Economic Growth Theory: Hampshire: Ashgate. [The book develops and refines the economic growth theory by Zhang (1999).]

Zhang, W.B. 2006. Growth with Income and Wealth Distribution: London: Macmillan. [The book 
systematically studies important issues related to growth and income and wealth distribution based on an alternative utility function proposed by Zhang.]

Zhang, W.B. 2008a. Monetary Growth Theory: Money, Interest, Prices, Capital, Knowledge, and Economic Structure over Time and Space. London: Routledge. [The book systematically studies important issues related to monetary economic growth based on an alternative utility function proposed by Zhang.]

Zhang, W.B. 2008b. International Trade Theory: Capital, Knowledge, Economic Structure, Money and Prices over Time and Space. Berlin: Springer. [The book systematically studies trade issues based on an alternative utility function proposed by Zhang.]

\section{Biographical Sketch}

Dr. Wei-Bin Zhang, born in 1961, teaches and does research at Ritsumeikan Asia Pacific University in Japan. His main research fields are nonlinear economic dynamics, theoretical economics, growth theory, monetary economics, regional and international economics, urban economics, East Asian industrialization, and Chinese philosophy. He has published more than 100 academic articles and authored 21 books.

He was brought up in China. He graduated from Department of Geography, Peking University. He finished graduate study at Department of Civil Engineering, Kyoto University in Japan. He obtained his Ph.D. in Economics at Department of Economics, University of Umeå in Sweden. He conducted research in Sweden from 1987 to 1998. 